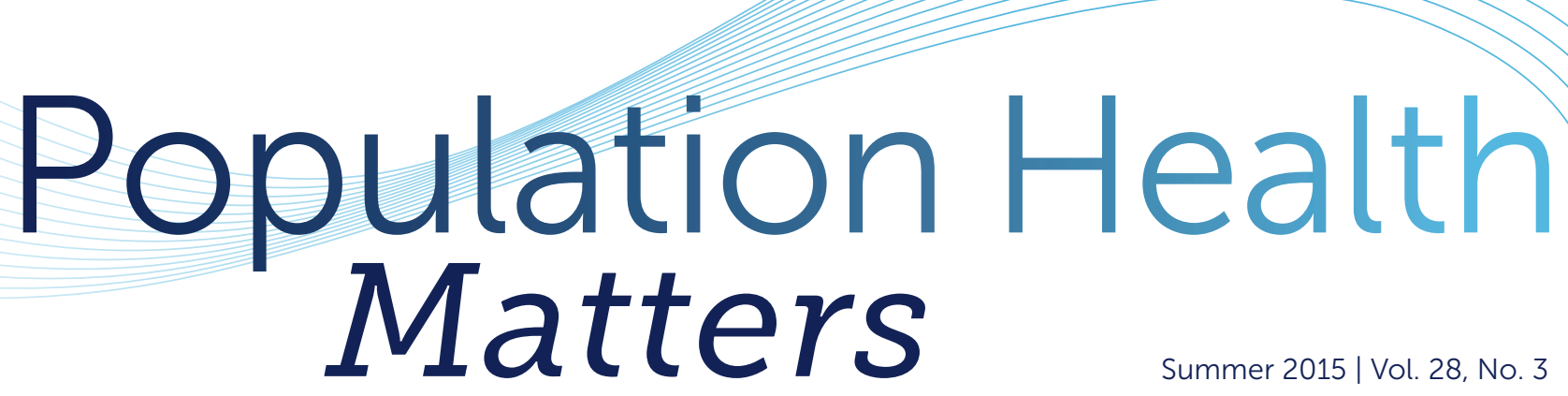

\title{
The Generation of Transformation
}

It used to be easy to give a commencement speech. You could tell a few jokes, praise the graduates, and exhort them to keep learning. Not today.

The 2015 graduates go into a health care world crying out for fundamental transformation. Not just tinkering with a broken system. The focus on how we organize, deliver and think about care needs to be based not on episodic care but rather on how we partner with patients to advance their health.

But this generation of health professionals will make a difference. I asked the graduates of Jefferson's six colleges of health sciences to question their role in a system that is more comfortable paying to cure sick patients than investing in efforts to keep people healthy.

As Esther Dyson said when she received an honorary degree from Jefferson this year, "Health care's actual mission has changed. It's not just curing the sick. It's creating health."

Dyson, who is one of America's foremost investors in health transformation, went on to say: "We need you to change the risks (for people) and if you do that you will have produced the most important, valuable asset on earth - people living happy, fulfilling and healthy lives."
This is precisely why at Jefferson we rewrote our vision statement last year. We're not tinkering with the past. We are reimagining healthcare, education and discovery. We'll do it to create unparalleled value for the people we serve, and we'll do it to be your most trusted healthcare partner.

This generation carries the pioneers and ambassadors of that vision. I'm deeply proud of our graduates, educated under the challenge to reimagine health. For us, that meant 316 in health professions, 89 in pharmacy, 414 in nursing, 56 in biomedicine, 52 in population health, and 278 in medicine. As a unique health science university, Jefferson is one of the nation's leaders in bringing these disciplines together as high-powered teams. That's where it starts, and these young professionals will understand it.

I believe they will lead the generation of health professionals that changes the DNA of healthcare. And I can't wait.

\section{Stephen Klasko, MD, MBA}

President and CEO

Thomas Jefferson University

and Jefferson Health

Reprinted from Dr. Klasko's blog: http://leadership.Jefferson.edu/blog/
The Generation of Transformation

The Stephen Klein Wellness Center as a Community-Centered Health Home

Jefferson Center for Interprofessional Education Creates TeamSTEPPS ${ }^{\circledR}$ Workshops for Patient Safety Training for Students.

Honoring the University of Delaware Medical Scholar Graduates

The 24th Annual Dr. Raymond C. Grandon Lecture: "Building a Culture of Health in America"

JCPH Class Night 2015.

Communication Skills Training for Patients and Healthcare Providers

Decision Support and Participation in the Jefferson Pancreas Tumor Registry

My Experience as a Jefferson College of Population Health Applied Health Economics and Outcomes Research Fellow.

Population Health Forums

ISPOR Annual International Meeting

JCPH Presentations

JCPH Publications.

$\mathrm{JCPH}$ in the News

Announcements \& Upcoming Events

Join the Grandon Society... 6

$\$ 100,000$ Hearst Health Prize Call for Applications..........................................................

Market Access Americas Congress .................16

Upcoming JCPH Forums. .17

\section{Open Positions}

Program Director and Faculty, Applied Health Economics and Outcomes Research...............13

Program Director, Healthcare Quality and Safety...... 


\section{The Stephen Klein Wellness Center as a Community- Centered Health Home - a partnership between Jefferson and Project HOME}

The mission of the Project HOME community is to empower adults, children, and families to break the cycle of homelessness and poverty, to alleviate the underlying causes of poverty, and to enable all of us to attain our fullest potential as individuals and as members of the broader society. We strive to create a safe and respectful environment where we support each other in our struggles for self-esteem, recovery, and the confidence to move toward self-actualization. Health and Recovery Services are an integral component of Project HOME's work to achieve this mission.

For the past 23 Years, Jefferson faculty, residents and students have partnered with Project HOME to provide primary care for people experiencing homelessness in safe havens such as the St. Elizabeth Wellness Center. The Center is located within a former church rectory in a medically underserved area of North Philadelphia. The service area is considered a high poverty area, with $43 \%$ of people living below $100 \%$ of the federal poverty level.

Project HOME's long-standing partnership with Thomas Jefferson University and Hospital is part of a growing trend among academic health centers that consider community-university partnerships a strategic imperative to achieve the Triple Aim of increased quality, decreased cost of care and improved patient experiences.

The Wellness Center's target population is characterized as experiencing very poor health and health care access relative to the general population with markedly high diabetes and cardiovascular disease prevalence, age-adjusted all-cause mortality, tobacco use, low birth weight, obesity among children, experiences of major depression, and poor utilization of oral health care.

In 2014, with New Access Point Health Resources and Service Administration (HRSA) funding to support a Federally Qualified Health Center (FQHC), health services transitioned from a free clinic model under Jefferson to a free-standing health center that is governed, owned and operated by Project HOME, with contracted physician services through Jefferson. The goal was to bring healthcare services under the governance, fiscal and operational control of Project HOME, without disrupting the patientprovider relationships that many patients had developed with their Jefferson physicians over the years. The Center is directed by a Community Board.

Project HOME's FQHC service delivery model recognizes the complex needs of people who are homeless. The model incorporates several best practices and approaches, including; comprehensive services spanning multiple service sites that are accessible to the homeless population; a multi-lateral approach to achieving the highest insurance enrollment rates possible; a personcentered "patient flow" from front desk to service provider(s) to follow-up; a staffing plan that emphasizes teambased care including the full integration of primary care with behavioral health services; a sliding fee discount scale that recognizes the very limited financial resources of the population served and has been implemented in such a way as to not "screen" out patients based on income; and a dedication to continuous quality improvement.

In December 2014, Project HOME moved out of St. Elizabeth's Wellness Center to the newly built, 28,000 sq. ft. Stephen Klein Wellness Center (the Center) at 22nd Street and Cecil B. Moore Avenue. The Center continues its commitment to address the health and wellness needs of people who are currently homeless, formerly homeless, and people living in the surrounding North Philadelphia community. The Center offers primary medical care, psychiatric services, nurse care management, individual, couples and group counseling, peer-led outreach and care coordination, healing touch, on-site legal counseling, housing counseling, health education, assistance with applying for health insurance benefits, a food pantry, laundry and shower facilities, and a fitness center and babysitting service managed by the Philadelphia Freedom Valley YMCA. A dental practice and pharmacy are planned to open there this summer.

The Center is a partnership between Project HOME, Thomas Jefferson University Hospitals, Inc.(TJUH), Sidney Kimmel Medical College's Department of Family and Community Medicine, the Middleton Partnership and Stephen Klein, its lead funder, and longstanding champion of this project. TJUH has shown its support with a $\$ 1$ million gift to the project.

The partnership between Project HOME, Jefferson, and the Center is an excellent example of the Community-Centered Health Home (CCHH). According to the Prevention Institute, "the communitycentered health home provides high quality health care services while also applying diagnostic and critical thinking skills to the underlying factors that shape patterns of injury and illness. By strategically engaging in efforts to improve community environments, CCHHs can improve the health and safety of their patient population, improve health equity, and reduce the need for medical treatment. The $\mathrm{CCHH}$ model advances a number of existing health care delivery models and practices, including the patient-centered medical home, as defined by the Patient-Centered Primary Care Collaborative, and the health home, as defined in the ACA." 1

In addition to high quality medical services, the $\mathrm{CCHH}$ adds a community dimension by collecting data on social, economic, and community conditions; aggregating health and safety data; systematically reviewing health and safety trends; identifying priorities and strategies with community partners; coordinating activity with community partners; acting as community health advocates; mobilizing patient populations; strengthening partnerships with local health care organizations, and establishing model organizational practices. The Project HOME-Jefferson partnership at the Center provides a 
unique opportunity to implement and evaluate the concept of the $\mathrm{CCHH}$.

\section{James D. Plumb, MD, MPH}

Professor, Department of Family and

Community Medicine

Thomas Jefferson University

Director, Center for Urban Health

Thomas Jefferson University Hospitals

James.Plumb@Jefferson.edu

\author{
Lara Weinstein MD, MPH \\ Assistant Professor of Family Medicine \\ Department of Family and \\ Community Medicine \\ Thomas Jefferson University \\ Lara.WeinsteinaJefferson.edu
}

Monica McCurdy PA-C, MHS

Vice President of Healthcare Services

Project HOME

monicamccurdy@projecthome.org

\section{REFERENCE}

1. Prevention Institute at the Center of Community Well Being. Community-Centered Health Homes: Bridging the gap between health services and community prevention.February 2011. http://www.preventioninstitute.org/component/jlibrary/article/id-298/127.html Accessed June 7, 2015.

\section{Jefferson Center for Interprofessional Education (JCIPE) Creates TeamSTEPPS ${ }^{\circledR}$ Workshops for Patient Safety Training for Students}

Numerous reports over the past few years have claimed that effective teamwork is essential to reduce medical errors and ensure patient safety. 1,2,3,4 Most recently, the Interprofessional Education Collaborative (IPEC), a group representing 6 major national healthcare professional associations, published the core competencies for interprofessional education and advised that students must be prepared to en ter the workplace with the knowledge and experience of working in effective teams. ${ }^{5}$ Thomas Jefferson University recognizes this need and has initiated a number of training programs to enable students, faculty and clinicians to become more proficient in working in interprofessional teams. The Jefferson Center for Interprofessional Education (JCIPE), which is dedicated to the advancement of interprofessional education and care and comprised of representatives of all components of the University and Hospital, has taken a leadership role in this endeavor. JCIPE has been presenting team training workshops based on TeamSTEPPS ${ }^{\circledR}$ (Team Strategies and Tools to Enhance Performance and Patient Safety) principles since May 2013.

TeamSTEPPS ${ }^{\circledR}$ is a program developed by the Department of Defense and sponsored by the Agency for Healthcare Research and Quality (AHRQ), with a goal to train healthcare professionals to work together effectively in teams to ensure patient safety. ${ }^{6}$ Each of the workshops emphasizes TeamSTEPPS ${ }^{\circledR}$ principles by focusing on the following skills: leadership, situational awareness, team support and communication skills (with a special focus at Jefferson on speaking up about a patient safety issue).

These workshops are presented at the Dr. Robert and Dorothy Rector Clinical Skills and Simulation Center (Simulation Center) to both Jefferson students and clinicians. Though Hospital staff are used to working in teams, they also have opportunities to hone their teamwork skills to maximize effectiveness and minimize error. Each workshop that JCIPE has presented has been designed to meet the needs of the audience, whether they are first-year students or experienced clinicians. The workshops range from 2 to 4 hours and usually follow the following format: a brief didactic introduction with video clips to demonstrate the core concepts, a simulation-based experience involving the learner as either a participant or an engaged observer, and other interactive components such as team-building exercises and issue-based brainstorming sessions. Two workshops are described here to illustrate the approach to interprofessional teamwork training.

The first TeamSTEPPS ${ }^{\circledR}$ workshop was held as a pilot for a volunteer group of students who had a moderate amount of clinical experience in their training. After the didactic introduction, video clips and team-building exercise, the students were challenged with two simulation cases to apply their knowledge and practice their team-based skills. One case was a patient with a cerebrovascular accident in the rehab gym who fell and had a seizure. This case required careful attention to the cervical spine to avoid further injury and attention to the brain to rule out subdural hematoma. It also involved a family member as part of the team. The case, which presented a problem new to students, required each member of the team to rely on their problem-solving skills as well as team skills to find the best solution to the problem. By participating in the simulation, students learned the role of each profession in managing the case and gained an appreciation for the skill set that each health professions student brought to the table. The second case involved a patient who experienced cardiac arrest in the MRI suite. This case focused on the TeamSTEPPS ${ }^{\circledR}$ principle of situational awareness, dealing with the restrictions to access in the MRI suite and the high-stakes interaction of team members in a cardiac resuscitation.

Another, more recent, workshop was conducted for students in the Health

Continued on page 4 
Mentors program, who have had very little clinical experience in their training. In this workshop, the scenario required students who had been doing a health screening to simulate the situation of being stranded in a mall after an explosion, with minimal equipment to tend to people with minor illnesses or injuries. Again TeamSTEPPS ${ }^{\circledR}$ skills were emphasized in the training and debriefings.

Regardless of the topic or audience, all workshops are interprofessional and engage the learner in active learning experiences maximized by facilitated debriefings. ${ }^{7}$ It is during these debriefing sessions that students and clinicians, with the help of the faculty facilitators, have an opportunity to reflect on their team skills, and assess how well the team managed the patients' care and how they interacted as team members. ${ }^{8}$ It is important to note that although the medical aspects of the cases are discussed, the emphasis is on team interaction. Participants have noted the value of these debriefings that allow them to focus on mastering effective teamwork in addition to solving the healthcare issue. Evaluations of the various workshops have consistently shown that the majority of participants mastered the knowledge content, thought that the workshops' objectives were met, and valued the opportunity to experience an interprofessional clinical simulation.

In the next Population Health Matters, there will be a description of the Team Training STEPPS ${ }^{\circledR}$ Workshops that JCIPE has delivered to Jefferson staff.

\author{
Alan T. Forstater, MD, FACEP \\ Director of Professionalism \\ Department of Emergency Medicine \\ TeamSTEPPS Faculty \\ Jefferson Interprofessional Education Center \\ Alan.ForstateraJefferson.edu
}

Elizabeth Speakman EdD, RN, CDE, ANEF Co-Director, Jefferson Center for Interprofessional Education

Associate Professor, Jefferson College of Nursing

Elizabeth.SpeakmanaJefferson.edu

\author{
AnneMarie Pettit MSN, RN \\ Instructor, Jefferson College of Nursing \\ AnneMarie.Pettit@Jefferson.edu
}

\author{
John Duffy MSN, RN \\ Associate Director, University Simulation \\ Director, Simulation and Clinical Skills \\ Jefferson College of Nursing \\ John.Duffy@Jefferson.edu
}

\section{REFERENCES}

1. Institute of Medicine. Crossing the Quality Chasm: A New Health System for the 21st century. Washington, DC: National Academies Press; 2001.

2. Health Professions Networks Nursing \& Midwifery Human Resources for Health. Framework for Action on Interprofessional Education \& Collaborative Practice. World Health Organization. http://whqlibdoc.who.int/hq/2010/WHO_HRH_HPN_10.3_eng.pdf?ua=1. 2010. Accessed July 3, 2015.

3. Kohn LT, Corrigan JM, Donaldson MS. Ed. To Err is Human: Building a Safer Health System. Committee on Quality of Health Care in America. Institute of Medicine. Washington DC: National Academies Press; 2000

4. Institute of Medicine. Committee on Quality of Health care in America. Crossing the Quality Chasm: A New Health System for the 21st Century. Washington DC: National Academies Press; 2001.

5. Core competencies for interprofessional collaborative practice. Report of an expert panel Interprofessional Education Collaborative. http://www aacn.nche.edu/education-resources/ipecreport.pdf. May 2011. Accessed July 3, 2015.

6. Clancy CM, Tornberg DN. TeamSTEPPS: Assuring optimal teamwork in clinical settings. Am J Med Qual. 2007; 22(3): 214-217.

7. Bonwell C. Active learning: Creating excitement in the classroom. https://www.ydae.purdue.edu/lct/HBCU/documents/Active_Learning_Creating_ Excitement_in_the_Classroom. Accessed July 3, 2015.

8. Fanning RM, Gaba DM. The role of debriefing in simulation based learning simulation in healthcare.J Soc Simulation Healthcare. 2007;2(2):115-125.

\section{Honoring the University of Delaware Medical Scholar Graduates}

\section{Commencement Address by Rob Simmons, DrPH, MPH, MCHES, CPH, Jefferson College of Population Health}

\section{May 30, 2015}

Thomas Jefferson University is the Medical School home for the state of Delaware. Each year, top undergraduate students in the health and social sciences at the University of Delaware (UD) come to Jefferson for their graduate education in Medicine, Nursing,
Health Professions, Pharmacy, Biomedical Sciences, and Public Health.

Three years ago, UD organized a Medical Scholars program for their top pre-medical students in various degree programs in the College of Arts and Sciences affiliated with the College of Health Sciences.
The program has grown rapidly and has approximately 90 UD students who commit to this scholarly elective through their four-year undergraduate degree program across the campus. These highly motivated students often have dual and even triple majors in addition to their participation in this scholarly elective. 
The Medical Scholars program is directed by David Barlow, PhD along with three undergraduate health sciences advisors. Several Jefferson medical and health science faculty share their health science careers with the UD Medical Scholars and serve as informal mentors. Jefferson College of Population Health (JCPH) Dean David Nash, MD, MBA has presented to the UD Medical Scholars on a number of occasions. Most of the scholars will begin their graduate health science education here at Jefferson in the coming year.

This year, the Medical Scholars program wanted to provide a perspective about public health and its synergy with medicine and asked Dr. Rob Simmons, Director of the Master of Public Health (MPH) program, to speak at its commencement. Some of the themes Dr. Simmons highlighted while sharing his public health experience included:
- The increasing diversity of our society and the importance of cultural humility, recognizing health inequities, and understanding and showing respect for various cultures, populations, and communities

- The root causes of both good and poor health as one addresses the "social determinants of health" as essential supportive systems for quality clinical care

- The commitment to lifelong learning given the explosion of technology that will greatly impact one's health and practice of healthcare

- The importance of interprofessional teamwork (working with other healthcare, public health and social system professionals) and the consideration of joint graduate degrees in related disciplines along with medicine
- The call to leadership and action as a future health professional to represent the patients and communities one serves and "make a difference"

- To follow one's passion, seek out mentors, share one's optimism, and leave a legacy of change to improve the health of our nation.

The UD Medical Scholars program is expected to maintain its rapid growth, in numbers and stature, and Jefferson faculty will continue to provide mentorship and support for our future generation of health leaders.

\section{DON'T MISS JCPH INFORMATION SESSIONS!}

\section{Learn More About Our Programs}

$\mathrm{JCPH}$ is hosting a series of convenient online and onsite information sessions to help introduce you to our degree and certificate programs in: Population Health; Public Health; Health Policy, Applied Health Economics and Outcomes Research; Healthcare Quality and Safety; and Healthcare Quality and Safety Management.

\section{ONLINE INFORMATION SESSIONS Click on program dates to link to registration.}

\author{
Master of Science and Certificate in Population Health \\ August 19, 2015 \\ 1:00 pm - 2:00 pm EDT \\ October 15, 2015 \\ 12:00 pm - 1:00 pm EDT
}

September 10, 2015

12:00 pm - 1:00 pm EDT

Population Health Academy

September 3, 2015

12:00 pm - 1:00 pm EDT

Master of Science and Certificate in Health Policy

September 15, 2015

12:00 pm - 1:00 pm EDT

October 22, 2015

12:00 pm - 1:00 pm EDT
Master of Science and Certificate in Applied Health
Economics and Outcomes Research

September 17, 2015

12:00 pm - 1:00 pm EDT

October 28, 2015

12:00 pm - 1:00 pm EDT

ON SITE INFORMATION SESSIONS Click on program dates to link to registration.

\section{Master of Public Health and Certificate}

September 15, 2015

5:30 pm - 7:00 pm

\section{Doctoral Program (PhD) in Population Health Sciences}

September 16, 2015

4:30 pm - 6:00 pm
October 28, 2015

5:30 pm - 7:00 pm
Master of Public Health and Certificate

October 7, 2015

12:00 pm - 1:00 pm EDT 


\section{The 24th Annual Dr. Raymond C. Grandon Lecture: "Building a Culture of Health in America"}

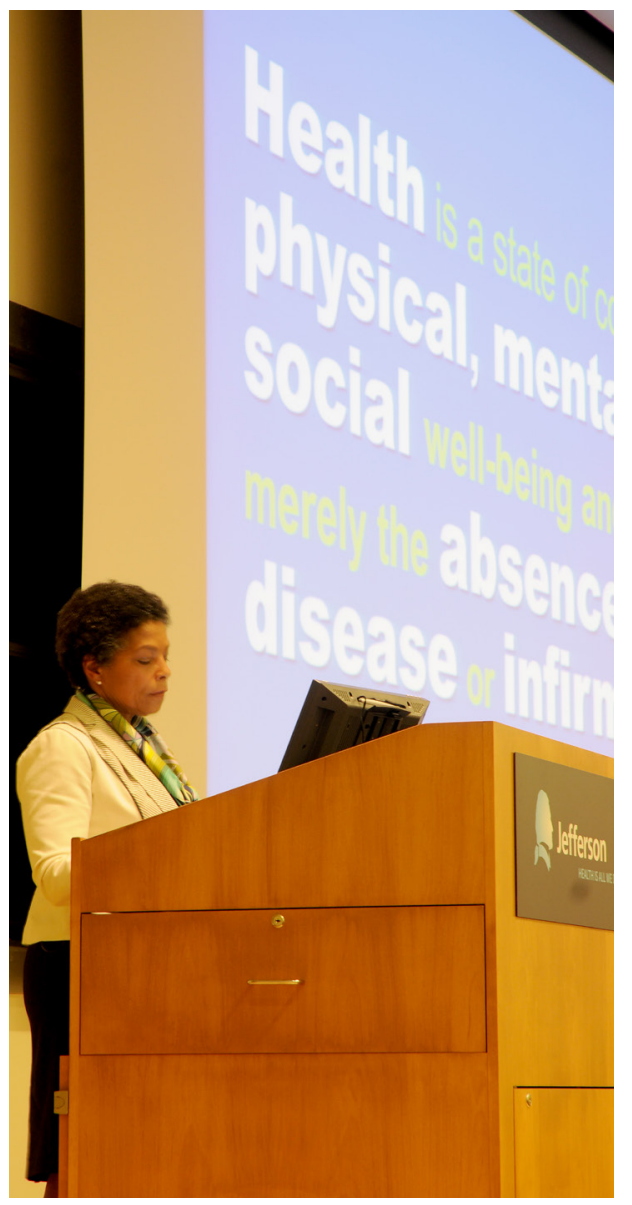

This year's Grandon Lecture featured Dr. Risa Lavizzo-Mourey, president and CEO of the Robert Wood Johnson Foundation (RWJF) since 2003. RWJF is the largest philanthropy in the U.S. solely dedicated to healthcare. Dr. Lavizzo-Mourey is a specialist in geriatrics and previously served as the Sylvan Eisman Professor of Medicine and Health Care Systems at the University of Pennsylvania. She also directed Penn's Institute on Aging and was chief of geriatric medicine. She has served as deputy administrator of what is now the Agency for Health Care Research and Quality (AHRQ), and worked on the White House Health Care Reform Task-Force.

Dr. Lavizzo-Mourey's Grandon presentation, "Building a Culture of Health in America," offered a broad perspective on how to improve health in the U.S. Lavizzo-Mourey envisions a culture of health that empowers communities to live healthy. RWJF is particularly focused on childhood obesity, health care coverage, and costs, quality and value of health care.

Lavizzo-Mourey shared examples of initiatives throughout the U.S. that have implemented measures to promote change and increase opportunities for communities to engage in healthier behaviors. For example, Philadelphia has shown a decline in childhood obesity among African American boys and Latinas. This was accomplished through changes in school wellness policies and incentives for new grocery stores in lower-income neighborhoods. Additionally, Philadelphia now requires all chain restaurants to post calorie information.

She challenged the audience to think about action areas including: ways to make health a shared value; fostering cross-sector collaborations to improve well-being; creating healthier and more equitable communities; and strengthening the integration of health-services and systems.

After the lecture, Dr. Lavizzo-Mourey was joined by Jefferson's CEO, Dr. Stephen Klasko, for an engaging question and answer segment at a special session for Grandon Society members.

To access slides and listen to the podcast for the Grandon Lecture, click here.

\section{JOIN THE GRANDON SOCIETY TODAY!}
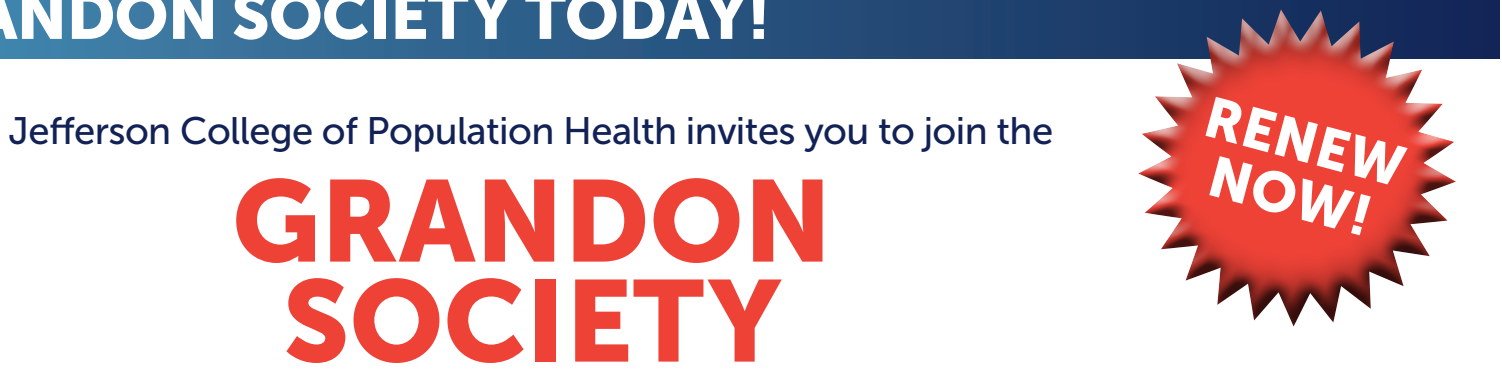

a membership organization for individuals and organizations focused on advancing population health.

The Grandon Society is designed for leaders throughout the healthcare sector who are dedicated to transforming the US health care system through collaboration, education and innovation. Benefits of membership include exclusive member-only programs and events, a member e-newsletter, and early notice and special registration rates for JCPH conferences and events. Memberships are available for individuals and

for organizations, with special rates for academic, non-profit and government institutions.

Become a member today and join us for the Grandon Society workshop on October 14, 2015 from 9:45 am - 11:45am, immediately following the Population Health Forum. This interactive session will feature, Minalkumar Patel, MD, MPH, Senior Vice President and Chief Strategy Officer at Horizon Blue Cross and Blue Shield of New Jersey.

For more information visit: Jefferson.edu/GrandonSociety

Questions?

Contact Alexis Skoufalos at 215-955-2822 or Alexis.Skoufalos@Jefferson.edu 


\section{(II) \\ HEARST HE A T T Thomas Jefferson University。 prize \\ IN PARTNERSHIP WITH \\ Jefferson College of Population Health \\ \$100,000 Hearst Health Prize Call for Applications !}

The Jefferson College of Population Health $(\mathrm{JCPH})$, in partnership with

Hearst Health, invites you to apply for the Hearst Health Prize. The winner will receive a $\$ 100,000$ cash prize in recognition of outstanding achievement in managing or improving population health.

The prize was created to help promote promising new ideas in the field that will help to improve health outcomes, and thus proliferate best practices more rapidly. The goal is to discover, support and showcase

the work of an individual, group, organization or institution that has successfully implemented a population health program or intervention that has made a measurable difference.

\footnotetext{
To learn about eligibility, criteria, and the application process visit: Jefferson.edu/HearstHealthPrize
}

\section{Questions? Email HearstHealthPrizeaJefferson.edu}




\section{JCPH Class Night 2015}

Every year prior to commencement, JCPH celebrates Class Night to acknowledge and honor the achievements of students who earn a Master's degree and graduate in the current academic year. Open to family, friends, and colleagues, Class Night also provides opportunities to recognize outstanding students, faculty and staff.

\section{This year the Distinguished Student} Award was presented to Elizabeth (Eli) deArmas, a graduate of the MPH program. Eli was recognized not only for her academic achievements, but her passion and devotion to public health activities and service. She was actively involved with Jefferson's Global Health Student Initiative Committee, where she was instrumental in organizing an international Ebola symposium and fundraiser. As vice president of JeffSAPHE (Student Activities for Public Health Education), she helped the organization to gain recognition for their team effort in fundraising for Ebola. Eli gave a heartwarming thank you to the JCPH community, who supported her and welcomed her when she first moved to Philadelphia from Miami. Eli has a background in journalism and, during her time at JCPH, she authored articles for Population Health Matters and contributed to the Nash on Health Policy blog.

\section{Brian Zepka was presented with the}

Distinguished Capstone Project recognition for "Addressing Hispanic Adolescent Mental Health in the Texas Border Region: A Policy Analysis." The purpose of this project was to provide informed advice to policy makers and facilitate decision-making concerning access to culturally competent mental health services for Hispanic adolescents in this region. As a result of this project, Brian was able to make recommendations for expanding the number of school counselors in each district. Brian is very

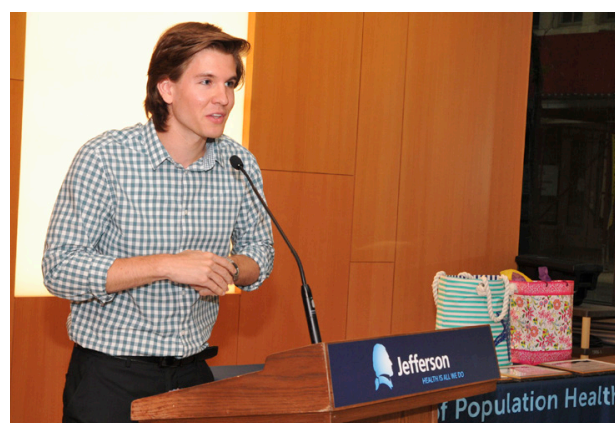

Brian Zepka, recipient of the Distinguished Capstone Award.

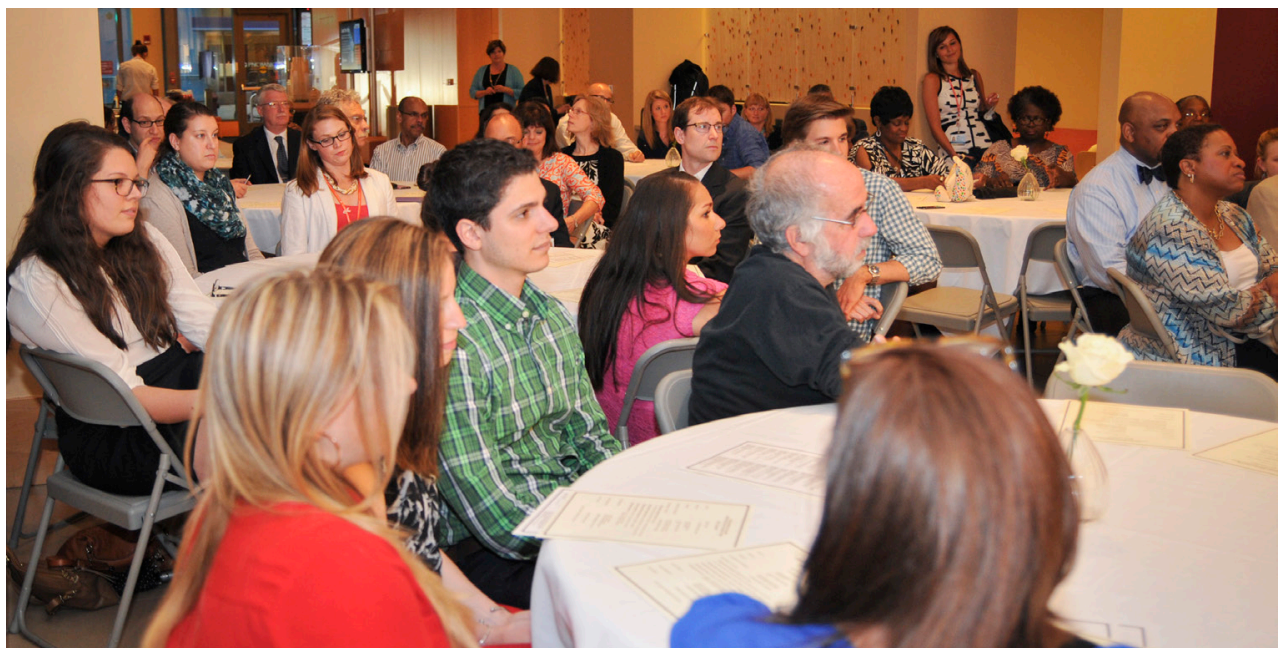

interested in communicable disease prevention, emerging infectious diseases, and health policy issues within the fields of mental health and environmental health. Brian interned at St. Christopher's Hospital for Children, where he worked on infection prevention education and policy issues. Brian was actively involved with JeffSAPHE community service projects.

Student access to practical, real-life professional experiences play an important role in public health programs. JCPH is fortunate to work with a number of outstanding organizations that support the $\mathrm{MPH}$ clerkships. This year JCPH presented the Distinguished Clerkship Sponsor to Public Citizens for Youth and Children (PCCY), a non-profit organization focused on improving the lives of children. Colleen McCauley, Health Policy Director, accepted the award and shared her encouraging words of wisdom to JCPH graduates.

Every year $\mathrm{JCPH}$ recognizes the exemplary contributions of faculty. Martha (Marty) Romney, RN, MS, JD, MPH, was this year's recipient of the Award for Teaching Excellence. Marty has been

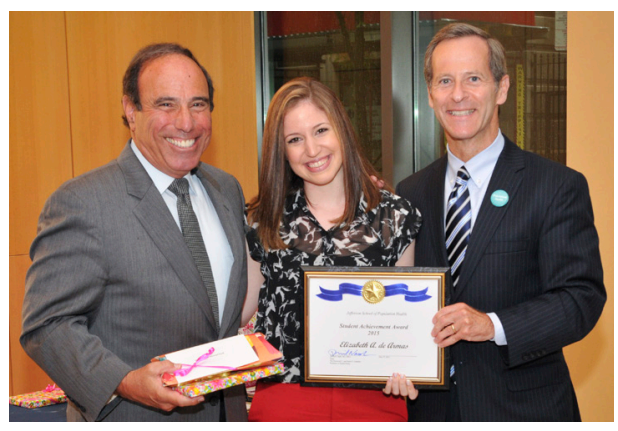

Eli DeArmas, recipient of the Distinguished Student award, with Dr. Simmons and Dr. Nash. a mainstay of the JCPH public health program since the School's inception and brings expertise and experience in key areas - cancer, obesity, workplace wellness, health disparities and cultural competency. Marty has an amazing set of credentials in law, public health, nursing and policy. She is currently working on completing her dissertation for the Doctor of Juridical Science in Health Law at the Widener University School of Law.

Marty's students describe her as "exceptionally knowledgeable, very well organized, always prepared, always positive, and always enthusiastic" about the subject matter. Marty's success is due to the fact that she creates an open, respectful environment in her class that supports the sharing of different perspectives.

Marty is deeply committed to service. She is a member of both the Pennsylvania and Philadelphia Bar Associations, having served as Secretary and Chair of the MedicoLegal Committee of the Philadelphia group. Nationally, she remains active the American Health Lawyers Association and the American Public Health Association. She works with the Maternity Care Coalition, serves on the Executive Committee of the College of Physician's Section on Public Health and Preventive Medicine, and sits on the Board of Directors of both the Greater Philadelphia Business Coalition on Health and the Health Promotion Council. At Jefferson, she serves on the University's Grade Appeal and Judicial Boards and chairs the JCPH Committee on Curriculum and Academic Policy. She also serves as President of the Columbia University School of Nursing Alumni Association. 
The JCPH Distinguished Service Award is intended to recognize individuals who perform the needed services for JCPH that are considered crucial but often unrecognized because they are hidden behind the scenes. This year, Nancy Chernett is the recipient of this award. In her role as Clerkship Coordinator and Capstone Coordinator, she has truly gone above and beyond the call of duty to assure that JCPH MPH students have a meaningful practicum experience, and that they are challenged to produce the best Capstone project possible.

Nancy is a gerontologist who specializes in family care giving and healthy aging; she is also a specialist in cultural competency in health and human services delivery. She is co-creator and instructor for the Cultural Humility and Competence for Health Professionals and Population Health course, and co-creator of the interactive learning modules in cultural competence for iCE - Jefferson's innovative online learning initiative. Nancy majored in psychology at Case Western Reserve University and went on to complete a master's degree in audiology, also at Case Western. She obtained her MPH from Ohio State University.
When Nancy first came to Jefferson in 2000, she worked with the University's Center for Applied Research on Aging and Health (CARAH), where she worked on a number of research projects that centered on family caregiving for persons with dementia. These projects often involved working in many Philadelphia communities and getting involved with non-profit agencies that serviced the needs of these communities. Her research at CARAH led to a series of well-received peer-reviewed publications which continued after she joined JCPH in 2010.

Nancy has helped to locate, evaluate, and place students in more than 70 different Clerkship sites throughout the Philadelphia region and coordinated 197 different Capstone Projects, including 12 where she served as Chair or Preceptor. This is an amazing accomplishment. She performed dual roles while serving as JCPH faculty, and initially was the first Director of Academic and Student Affairs.

When not teaching, researching, mentoring or supervising Clerkships and Capstone Projects, Nancy devotes herself to various humanitarian projects and volunteer work. Her energy and willingness to work on behalf of others is awe-inspiring. She is an activist and investor in the Hunger Project,

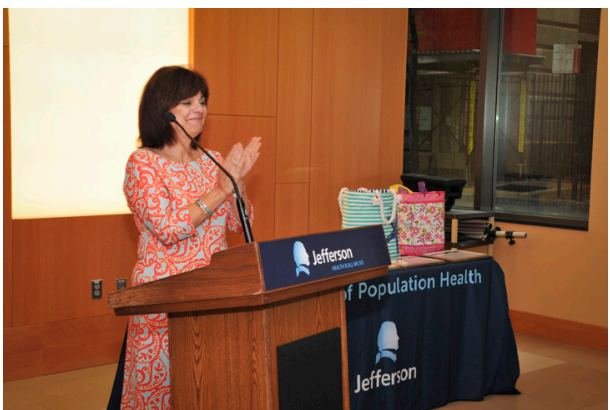

JCPH Clerkship and Capstone Coordinator, and Instructor Nancy Chernett

and actively involved in the Center for Advocacy for the Rights and Interests of the Elderly (CARIE) and supports Eldernet of Lower Merion Township. She is a trained facilitator of the Pachamama Alliance's "Awakening the Dreamer, Changing the Dream," a symposium committed to bringing forth an "environmentally sustainable, socially just, and spiritually fulfilling presence on the planet."

Nancy will retire this July. She has certainly been an enormous asset to JCPH and we thank her for being an inspiration to students and colleagues. She will be sorely missed by all.

To access capstone presentations of recent $\mathrm{MPH}$ graduates click here.

\section{Communication Skills Training for Patients and Healthcare Providers: A Proposed Blend of Performance Studies, Theatre and Communication Strategies}

Chronic health conditions pose challenges for patients and healthcare providers alike. As rates of diabetes and heart disease climb worldwide health educators have begun to use theatre, now accepted internationally as an effective intervention in infectious disease education, as a tool for teaching people how to understand and manage their chronic diseases. Examples of such programs include diabetes education in $\mathrm{Fiji}^{1}$ and stroke education in South Africa, ${ }^{2}$ where health educators are building on the previous success of theatre and infectious disease education.

As theatre gains recognition as an effective health teaching tool, it should be explored as a way to reach individuals suffering from chronic health conditions like diabetes and heart disease, with relevant, correct and timely information. As a teaching method, theatre is particularly useful among low-literacy and low health-literacy populations. ${ }^{3}$ It engages an audience and participants on a visual, auditory and emotional level, improving the likelihood of information comprehension and retention. ${ }^{3}$ Accessible information is essential to improving health outcomes, and novel initiatives are necessary to achieving this goal. Improvisational Theatre is a type of theatre during which the performance is created the moment it is performed, requiring participants to remain present, responsive and engaged. ${ }^{4}$ This level of engagement between healthcare providers and patients during discussions about diagnosis, treatment or behavior change increase the likelihood that when a patient leaves an appointment they will retain the correct and necessary information to properly care for their condition.

Based on frameworks from the Communication Accommodation Theory ${ }^{5}$ and Goffman's Theory of Presentation of Self in Everyday Life, ${ }^{6}$ this project hypothesizes that using created or improvised theatre programs will improve self-efficacy in older adults who suffer from chronic ailments and, at the same time,

Continued on page 10 
improve communication skills in healthcare providers who work with older patients.

A review of the literature on theatre and health education initiatives, specifically those focused on chronic diseases, revealed implications for improving provider-patient communication about chronic diseases and methods used to create health communication-focused theatre workshops.

All theatre projects identified in the literature review emphasized the need for cultural competence. For example, character interactions on stage must be culturally relevant and appropriate for messages to be effective, and must reflect cultural taboos regarding behavior. Though multiple types of theatre used for communicating about health were identified, Applied Theatre in particular was cited for its efficacy because it sustains information retention through emotions and sensory experience. ${ }^{2}$ The literature review also suggested that improvisational communication techniques could be a useful method for discussing barriers to and strategies for behavior change, ${ }^{7}$ indicating that this technique would be beneficial for chronic disease management.

Based on the outcome of this literature review, proposed next steps include a pilot Health Communication and Improvisational Theatre workshop to determine how improvisational theatre techniques can enhance doctor-patient communication regarding chronic disease management within the healthcare system in the United States. In 2012, chronic conditions -- including heart disease, lower respiratory disease, cerebrovascular disease, diabetes and nephritis --

represented 5 of the top 10 causes of death among Americans age 65 and older, and 6 of the top 10 causes of death among those 55 to 64, indicating that new modes of communication are necessary in order to effectively reach them. ${ }^{10}$

\section{Figure 1. Types of theatre used in chronic disease health education}

\begin{tabular}{|c|c|c|}
\hline Type of Theatre & $\begin{array}{l}\text { Disease } \\
\text { Process }\end{array}$ & Location \\
\hline $\begin{array}{l}\text { Applied Theatre } \\
\text { (Theater practiced in a specific social context, } \\
\text { with participants who have a vested interest in the } \\
\text { performance topic) }\end{array}$ & Stroke & $\begin{array}{l}\text { South } \\
\text { Africa }^{2}\end{array}$ \\
\hline $\begin{array}{l}\text { Community Theatre } \\
\text { (Theatre practiced with the intent of engaging a } \\
\text { community in a particular message) }{ }^{1}\end{array}$ & Diabetes & $\mathrm{Fiji}^{1}$ \\
\hline $\begin{array}{l}\text { Commercial Popular Theatre } \\
\text { (Theater produced for the purpose of entertainment) }^{9}\end{array}$ & HIV & Uganda $^{9}$ \\
\hline $\begin{array}{l}\text { Theatre for Development } \\
\text { (Theatre used for the purpose of achieving development } \\
\text { goals, a subcategory of Applied Theatre) }\end{array}$ & HIV & Uganda $^{9}$ \\
\hline
\end{tabular}

Workshops would focus on teaching how to use improvisational theatre techniques in the healthcare setting to improve patient engagement. Existing work on Theater and Health Communication suggested the following curriculum development components for workshops: 1) Establishment of physical space, ground rules and "safe" feeling; 2) Warm-ups: energy and focus, trust work, and bridge work; 3) Improvisation; 4) Activating material, and 5) Performance feedback. ${ }^{11}$ The review indicated that necessary elements for improvisation exercises include focus, side-coaching, evaluation and points of observation. ${ }^{12}$

Goals for successful curricula include, 1) Creation of safe spaces for dialogue; 2) Exploration of choices and consequences, then practice for real life; 3) Enhancement of communication and decision-making skills; 4) Use of multiple perspectives as a positive tool for problem solving, and 5) Risk-taking in fictional worlds in order to learn to take action in one's own life. ${ }^{11}$

This literature review was limited by the small number of studies related to the topic of theater and health communication, particularly in the United States. Additionally, the utilization of theater as a method of improving health communication may not be generalizable to all cultures, as selfexpression and communication have strong cultural components.

\section{Rachel Thomas, MPH '12}

Schweitzer Fellow For Life rachel.thomas@Alumni.Jefferson.edu

\section{Pamela Zubow Poe, PhD}

Lecturer, Thomas Jefferson University Pamela.Poea Jefferson.edu

\section{REFERENCES}

1. Szmedra P. Using community theatre to promote diabetes education and prevention in Fiji. Diabetes Voice 2013; 58(1): 22-25. https://www.idf.org/ sites/default/files/attachments/DV0113-szmedra.pdf. Accessed March 22, 2015.

2. Stuttaford M, Bryanston C, Hundt GL, Connor M, Thorogood M, Tollman S. Use of applied theatre in health research dissemination and data validation: a pilot study from South Africa. Health (London). 2006;10(1):31-45. DOI: 10.1177/1363459306058985.

3. Blair C, Valadez JJ, Falkland J. The use of professional theater for health promotion including HIV/AIDS. J Dev CommunStudies 1999;10(1):9-15.

4. Family Health International (FHI). Theater-Based Techniques for Youth Peer Education: A Training Manual. Arlington, VA: FHI; 2005. 
5. Griffin E, Ledbetter A, Sparks G. A First Look at Communication Theory. McGraw-Hill. 2014. http://www.afirstlook.com/edition_7/theory_list. Accessed March 28, 2015.

6. Schechner, R. Performance Studies: An Introduction. 2nd Edition. New York, Routledge; 2002.

7. USAID's Infant and Young Child Nutrition Project. Community theater for improved nutrition: a guide for program managers and theater groups. 2011. http://iycn.wpengine.netdna-cdn.com/files/IYCN_community_theater_071511.pdf. Accessed March 28, 2015.

8. Prendergast, M. and Saxton, J. Applied Theatre, International Case Studies and Challenges for Practice, Intellect Publishers, Briston, UK, 2009 , pg 6

9. Frank, M. Theatre in the service of health education: case studies from Uganda. New Theatre Quarterly. 2009;12(46):106-115. http://journals. cambridge.org/action/displayAbstract?fromPage=onlinegaid=3023304\&fileld=S0266464X00009933. Accessed March 28, 2015.

10. CDC. Ten Leading Causes of Death and Injury. 2014. http://www.cdc.gov/injury/wisqars/leadingcauses.html. Accessed February 20, 2015

11. Rohd, M. Theatre for Community, Conflict and Dialogue. Portsmouth, NH: Heinemann; 1998.

12. Spolin V. Improvisation for the Theater, A Handbook of Teaching and Directing Techniques. Northwestern University Press; 1999.

\section{Decision Support and Participation in the Jefferson Pancreas Tumor Registry}

A Jefferson multi-disciplinary research team recently assessed the effect of a novel decision support intervention on patient participation in the Jefferson Pancreas Tumor Registry (JPTR), a specialty cancer registry that was established in 2008 and is maintained by the Department of Surgery of Thomas Jefferson University Hospital (TJUH). JPTR recruitment involves providing eligible patients with print information about the registry, obtaining consent, and completing a baseline survey questionnaire that records personal and family background and selected medical history, lifestyle, occupational and environmental exposures. From February to December 2011, a total of 175 patients with pancreatic tumors who underwent resection at TJUH were invited to participate in the JPTR. During this period, about $25 \%$ of patients treated in the Department of Surgery at TJUH consented and completed the JPTR baseline survey questionnaire.

Specialty cancer registries provide important information that can be used to learn about disease etiology and discover new approaches to prevention and treatment. Recruitment to specialty registries has been challenging; and finding ways to maximize participation is an important problem in cancer research. The study described here was designed to assess the impact of the Decision Counseling Program ${ }^{\odot}$ (DCP), a software program designed to aid in shared decision-making, on recruitment to the JPTR.

The DCP can be used by a trained health professional to help patients clarify personal values and preferences related to any health decision (e.g., whether or not to participate in a cancer registry). Using the DCP, a healthcare provider may meet with a patient, review important information about the specific health decision under consideration, explore the pros and cons associated with available options, identify important factors that influence decision making, weigh the influence of relevant factors, clarify the patient's preferred option, and produce a 1-page summary of the session for use in shared decision-making.

The research team identified 51 patients who underwent surgical resection for pancreas cancer, had not registered for the JPTR and returned to the clinic for a 1-month postoperative follow-up visit. A trained health educator met with an Intervention Group comprised of 20 patients who consented to participate in the decision-making study. Information about the JPTR was reviewed and participants completed an interactive exercise using the DCP to clarify personal preference related to registration in the JPTR. A Control Group was retrospectively identified, which included a convenience sample of 20 patients who had not participated in the decision-making study. Both study groups were comparable with respect to demographic background and disease stage. At 90 days, patients in both groups were contacted to determine how many had completed the JPTR survey.

At the conclusion of the study, we found that JPTR participation was significantly higher in the Intervention Group than in the Control Group (55\% vs. 10\%, $p=0.01$ ). Frequency analyses of the decision counseling showed that the distribution of pro and con decision factors did not differ markedly between participants and nonparticipants (15 pros and 10 cons versus 12 pros and 10 cons, respectively). Closer inspection of patient decision factors, however, revealed that the magnitude of importance assigned to pro factors was substantially greater among participants than nonparticipants.

The importance of benefiting others was mentioned more often as a primary factor in decision making among participants than nonparticipants. This finding highlights the role of altruism as a motivating force for registry participation. We also noted that while concerns related to the complexity and time involved for the registration process were cited by both participants and nonparticipants, these factors tended to be identified as secondary or tertiary factors in both groups. JPTR participants did not express concern about the confidentiality of registry information, but nonparticipants did have concerns. Both registry participants and nonparticipants identified feeling overwhelmed by the recovery process as a barrier to joining the JPTR. However, nonparticipants were more likely to identify this barrier as a primary decision factor.

Findings from the study reported here are consistent with the view that more proactive strategies are more likely to generate higher participation in tumor and cancer registries. We believe that efforts to increase participation in the JPTR, and perhaps other specialty registries, may benefit from efforts to provide decision support, minimize the burden of registration, address concerns

Continued on page 12 
about data confidentiality, and engage patients in the registration process at a time when they feel a greater sense of physical and emotional well-being.

\section{Ronald Myers, PhD, DSW \\ Professor \\ Department of Medical Oncology \\ Division of Population Science \\ Thomas Jefferson University \\ Ronald.Myers@Jefferson.edu}

\author{
Harish Lavu, MD, FACS \\ Associate Professor \\ Department of Surgery \\ Thomas Jefferson University \\ Harish.Lavu@Jefferson.edu
}

Charles J. Yeo, MD

Professor

Samuel D. Gross Professor of Surgery

Chair, Department of Surgery

Co-Director, Pancreas, Biliary, and

Related Cancer Center

Thomas Jefferson University

Charles.Yeo@Jefferson.edu

Scott W. Keith, PhD

Assistant Professor

Department of Pharmacology and

Experimental Therapeutics

Division of Biostatistics

Thomas Jefferson University

Scott.Keith@Jefferson.edu
Anna Quinn, MPH, RYT

Clinical Research Coordinator III

Medical Oncology

Division of Population Science

Thomas Jefferson University

Anna.Quinn@Jefferson.edu

\section{RESOURCES}

1. Myers et al. Decision counseling and participation in a cancer registry. J Registry Management. $2014 ; 41$ (4):196-200.

2. Jefferson Pancreas Tumor Registry

3. Center for Health Decisions, Decision Counseling Program

\section{My Experience as an Applied Health Economics and Outcomes Research Fellow at JCPH}

The increasing magnitude and intricacy of the current global economic and reimbursement environments pose challenges for researchers working in the health economics and outcomes research (HEOR) space. It is essential that professionals working in the health economics and market access (HEMA) sector have the knowledge and competencies to conceptualize, evaluate and disseminate evidence-based research, as well as to improve healthcare decision-making processes. To strengthen my HEOR research competencies and expand my knowledge and skills in health policy development, I applied for the Jefferson College of Population Health's (JCPH) collaborative Fellowship program with Ethicon Inc., Johnson \& Johnson. My objectives for the HEOR Fellowship were to participate on diverse HEOR development teams, to gain fundamental knowledge and direct experience in health policy and global reimbursement systems, and to understand the multi-sectorial dynamics, implications and opportunities to enhance the HEOR research and marketing strategies in the surgical healthcare space.

Under the academic and industry mentorship of Dr. Martha Romney, Dr. Vittorio Maio and Dr. Joseph Jackson of $\mathrm{JCPH}$ and Dr. Anuprita Patkar of Ethicon Inc., I have been involved in an extensive range of diverse projects, ranging from more advanced technical components of HEOR research to the development of HEMA strategies in medical devices. Through these opportunities I have provided substantive contributions to manuscripts resulting in salient publications including "Gastrectomy and D2 Lymphadenectomy for Gastric Cancer: A Meta-Analysis Comparing the Harmonic Scalpel to Conventional Techniques" in the International Journal of Surgical Oncology, and an opinion piece, "Gap between Evidence and Patient Access: Policy Implications for Bariatric and Metabolic Surgery in Treatment of Obesity and its Complications" on journal PharmacoEconomics. I also developed an economic budget impact model on spinal

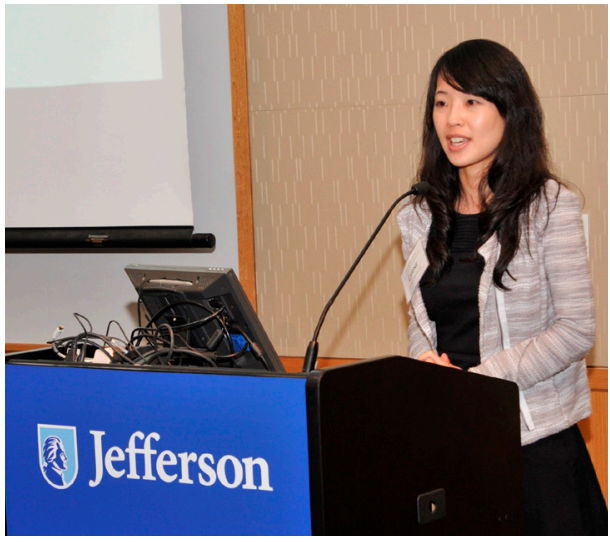

Carine C.W. Hsaio BSPharm, MHS

fusion procedures for adult deformity and adolescent scoliosis that is now being deployed worldwide. These are several examples of the breadth of research techniques, surgical and therapeutic areas, and multidisciplinary collaborations I have engaged in during the course of my Fellowship.

Coming from a pharmacy background, this Fellowship has provided the 
opportunity for me to assess the subtle but profound differences of HEOR work in pharmaceutical and medical device industries. While the research principles are similar, HEMA work in the medical device industry faces the challenges of shorter product life cycle development, the limited clinical and economic data, and the increasingly complex global reimbursement ecosystem. Strategic conceptual plans including proactive identification and data access, creative leveraging of existing information to develop evidence-based development portfolios to conduct compliant and scientifically rigorous research are paramount.

In addition to the meaningful research opportunities, the Fellowship also supported extensive development opportunities and forums to learn from international HEOR researchers, regulators and policy makers and to extend my professional network. These included the JCPH's annually sponsored Population Health Colloquium, the International Society for Pharmacoeconomics and Outcomes Research Conference, the Health Technology Assessment International Conference, the Medical Device Coverage and Reimbursement Conference, and the American Society for Metabolic and Bariatric Surgery Obesity Week. The educational opportunities heightened my awareness and insights about the complexity, magnitude and critical nature of various issues and advances in related areas. In addition, under the introduction from Dr. Romney, I was able to meet with Dr. Janine Kyrillos, an internist and the Director of the Comprehensive Weight Management

Program at Thomas Jefferson University Hospital. It was a wonderful experience to speak with a critical thought leader in the field to understand the key challenges of the patient referral system to bariatric surgery and obesity management programs, as well as to discuss how we can best integrate HEOR research to improve access for patients.

The JCPH Applied Health Economics and Outcomes Research Fellowship has expanded and enhanced my research and policy development capacities and prepared me for a career as a HEMA professional in the healthcare industry.

For more information on the AHEOR Fellowship program click here.

Carine C.W. Hsaio, BSPharm, MHS

JCPH Applied Health Economics and Outcomes Research Fellowship Alumna

Carine will continue her work at Ethicon in a new position this Fall.

\section{PROGRAM DIRECTOR AND FACULTY APPLIED HEALTH ECONOMICS AND OUTCOMES RESEARCH JEFFERSON COLLEGE OF POPULATION HEALTH THOMAS JEFFERSON UNIVERSITY}

Jefferson College of Population Health, one of six schools of Thomas Jefferson University, a major academic health center located in Philadelphia, PA, is seeking a leader and educator for its academic and professional programming in applied health economics and outcomes research (AHEOR).

As a ranked faculty member, the Program Director oversees curricular and instructional integrity and quality of the College's Certificate and Master of Science programs in Applied Health Economics and Outcomes Research, unique online academic offerings that aim to prepare professionals in the measurement, use and interpretation of economic and non-economic outcomes of healthcare interventions. The position is also responsible for program promotion and student recruitment; supervision and recruitment of full-time and adjunct faculty who teach in the program; and oversight of content and development for professional (non-credit) offerings in applied health economics and outcomes research. The Program Director serves as the College/University's major advocate and spokesperson for national and international trends related to this increasingly important field of study and practice.

The successful candidate is expected to teach courses in the academic program, to supervise PhD dissertations and MS Capstone research projects in the area of health outcomes research, and to engage in scholarship that leads to peer-reviewed publications.

The ideal candidate will hold a PhD in a relevant field and have academic-related experience in teaching, research, and curriculum design in addition to practical work experience in applied health economics and outcomes research. Depending on the candidate's area of expertise and current professional activities, this position can be configured as either a full-time or part-time opportunity in the Jefferson College of Population Health.

To apply for this position, please send curriculum vitae by e-mail to Caroline Golab, PhD, Associate Dean for Academic and Student Affairs, Jefferson College of Population Health: caroline.golabaJefferson.edu. Additional information about the Jefferson College of Population Health can be found at Jefferson.edu/PopulationHealth. 


\section{PROGRAM DIRECTOR, HEALTHCARE QUALITY AND SAFETY JEFFERSON COLLEGE OF POPULATION HEALTH THOMAS JEFFERSON UNIVERSITY}

Jefferson College of Population Health, one of six schools of Thomas Jefferson University, a major academic health center located in Philadelphia, PA, is seeking a leader and educator for its academic and professional programming in healthcare quality and safety.

This full-time faculty position oversees curricular and instructional integrity and quality of the College's Master of Science in Healthcare Quality and Safety (MS-HQS) degree program, a unique academic offering offered online to a national audience. The position is responsible for program promotion and student recruitment, including coordination with affiliated organizations such as the American Association for Physician Leadership; supervision, evaluation and recruitment of full-time and adjunct faculty who teach in the program; periodic review and evaluation of program content and learning outcomes; and oversight of content and delivery for professional (non-credit) offerings in healthcare quality and safety.

The successful candidate is expected to teach courses in the academic program, supervise students' Capstone Projects, and participate in the College's efforts to promote continuing professional education in healthcare quality and patient safety.

The ideal candidate will have extensive practical experience in the structuring and implementation of healthcare quality and safety in healthcare systems as well as experience in curriculum design, teaching and research related to healthcare quality and safety. The preferred candidate will have held leadership positions in a large healthcare system, will have a broad and integrated view of clinical medicine, and will hold an MD/DO degree in addition to an advanced degree in management or leadership with a concentration in quality and safety.

The Program Director will serve the College and University as the major interpreter of and spokesperson for national and international trends related to this growing and important field of study and practice.

To apply for this position, please send curriculum vitae by e-mail to Caroline Golab, PhD, Associate Dean for Academic and Student Affairs, Jefferson School of Population Health: caroline.golab@Jefferson.edu. Additional information about the Jefferson College of Population Health can be found at Jefferson.edu/PopulationHealth.

\section{POPULATION HEALTH FORUMS}

\section{Changing the Health Care Cost Discussion from "How Much?" to "How Well?}

\author{
A. Mark Fendrick, MD \\ Director, Center for Value-Based \\ Insurance Design \\ Professor, Internal Medicine \\ School of Medicine \\ Professor, Health Management and Policy \\ School of Public Health \\ University of Michigan \\ April 8, 2015
}

Dr. Fendrick is director of the Center for Value-Based Insurance Design at the University of Michigan where he oversees the center's role in leading and advocating for the development, implementation, and evaluation of innovative health benefit plans. Value-Based Insurance Design ( $V$-BID) is described by the Center as plans that "align patients' out-of-pocket costs, such as co-payments, with the value of the services...and is built on the principle of lowering or removing financial barriers to essential, high-value clinical services. ${ }^{11}$ Dr. Fendrick's research focuses on how clinician payment and consumer engagement initiatives impact access to care, quality of care, and health care costs

Dr. Fendrick strongly believes in shifting the discussion from "how much" we are spending on health care to "how well" we are spending on health care. How does this happen? He first described ways in which research should be translated into policy. For example, innovations to prevent and treat disease have led to reductions in morbidity and mortality; despite these advances, cost growth is the main focus of healthcare reform discussions. Additionally, underutilization of high-value services persists despite evidence of clinical benefits.

Fendrick explained that consumer costsharing is key to encouraging clinically appropriate use of health services. There is growing evidence that increases in cost-sharing leads to a reduction in the use of essential services and impacts behavior in healthcare utilization. "If you look at the typical benefit design, you will see cost-sharing is done in as one-sizefits-all."

Fendrick went on to discuss the impact of high co-pays and coinsurance, which have a profound effect on medication 
adherence in important classes of drugs. High co-pays also increase disparities among economically vulnerable individuals and those with chronic conditions.

"Clinical nuance" is a term that Fendrick weaves into $\mathrm{V}$-BID as an important characteristic of a plan and critical to healthcare transformation. Basically, clinical nuance is focused on making sure that the patient gets to the right provider at the right time - the service depends on who receives it and who provides it. "Clinical nuance acknowledges that medical services are different in the clinical benefit they produce, in the setting of a payment and benefit design system that doesn't acknowledge them." Implementation of clinical nuance sets the consumer cost-sharing level based on the clinical benefit, not the acquisition price of the service.

Recent findings reveal that $\mathrm{V}$-BID plans tend be more generous; target high-risk individuals; offer wellness programs; and have a greater impact on adherence than other plans. ${ }^{2} \mathrm{~V}$-BID is included in the Affordable Care Act (ACA), and Selected Preventive Services without Cost-Sharing (ACA Sec 2713)is the more popular and non-partisan aspect of ACA. Fendrick concluded his presentation by describing the ongoing policy and implementation challenges and achievements.

\section{Grandon Society Workshop}

Dr. Fendrick's dynamic and humorous demeanor helped to provide a lively session for Grandon Society Members. He emphasized that it is far easier to cut cost than to reduce waste. He encouraged the audience to move away from the "one size fits all" model. He stated that the healthcare delivery system is the single best employer to put V-BID in place. Fendrick also shared information on the Coalition for Smarter Health Care - an advocacy branch of the Center aimed at furthering consumer access to high-value, affordable services.

\section{REFERENCES}

1. Center for Value-Based Insurance Design. What is Value-Based Insurance Design? http://vbidcenter.org/about-us/.

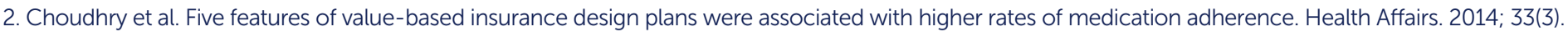

\section{ADDITIONAL RESOURCES:}

Fendrick, AM. Ayanian JZ. Smarter consumer cost sharing using clinical nuance. Harvard Business Review. November 15, 2013.

Chernow M, Schwartz JS, Fendrick AM. Reconciling prevention and value in the health care system. Health Affairs Blog. March 11, 2015.

\section{Integrating Population Health into Residency Training: Challenges and Opportunities}

\section{Arthur Boll \\ Chief Executive Officer \\ Germane Solutions \\ May 13, 2015}

Arthur Boll is CEO of Germane Solutions, a healthcare consulting and technology firm primarily focused on graduate medical education (GME). Mr. Boll is a nationally recognized expert in all facets of GME issues including new program development, operations and finance, and infrastructure. He has worked on over 700 GME-related projects and has performed multiple new residency program planning engagements.

Mr. Boll began his presentation by explaining that much of today's resident training is based on episodic encounters. Change is needed to move to a continuity of care model with a focus on outcomes management, population health management and targeted measures to improve health status. Not only will this drive quality and safety, but it will set in motion paradigm change in medical education.
In order to make meaningful changes in GME programs, it is critical to understand population health management. Boll defined population health management, changing perspectives, and the link to clinical care. He explained how providers must be able to identify subpopulations of patients who benefit from additional services, and where payers will recognize the value of care and health outcomes. He discussed the model of "high performance" care teams that utilize automated reports, alerts and communications to minimize manual tasks. This approach improves the quality of patient care and allows systems to deploy clinical and coaching talent for targeted sub-populations that require more intensive supports.

Boll discussed the relationship between residency programs and patient-centered medical homes (PCMH). To make a training program for PCMH successful, there must be continuity at the resident level; significant, on going clinical experience; and different roles built into the program that will evolve over the period of the resident's clinical training and experience, and ensure that resident is linked to patient outcomes.

Boll went on to emphasize process work flows and tools for PCMH with care coordination as the foundation of $\mathrm{PCMH}$ and residency training. He also discussed the need for residents to be trained on social needs as part of the population health journey. Technologybased programs can help residents to easily monitor and track these issues. Boll acknowledges that PCMH will ultimately focus on priorities that payors will fund.

Boll explained the importance of measuring and improving performance. Residents, faculty, program directors and health system executives will need information to manage various aspects of PCMH training. He believes residency involvement in $\mathrm{PCMH}$ should be a high priority in clinical training.

Continued on page 16 
In summary, Boll made the business case for population health management in residency programs. For example, better outcomes include reduced preventable hospitalizations and increased payor mix. New revenues would include risk management contracts and generally enhance reimbursement. His take-home messages are that an overlay technology system must be built, curriculum must be changed, and most important, "it's not just medical, it's social."

\section{Market Access Americas Congress September 30 - October 1 Philadelphia.}

See Dr. Nash at the Market Access Congress where payers, industry, providers and patient organizations will discuss how to maximize access and realize value in evidence-based research.

For information regarding the academic/government discount rate, contact kkusova@healthnetworkcommunications.com

\section{JCPH PRESENTATIONS AT ISPOR}

\section{0th Annual Meeting of the International Society of Pharmacoeconomics and Outcomes Research May 18-20, 2015}

Alcusky M, Ferrari L, Rossi G, Liu M, Maio V. Attitudes towards collaboration among nurses and physicians practicing in newly established medical homes.

Alcusky M, Keith SW, Karagiannis T, Rabinowitz C, Louis DZ, Maio V. Is Metformin exposure associated with improved survival in health and neck cancer patients? A large population-based cohort study.

Alcusky M, Cannon-Dang E, Steele D, DeSimone Jr. JA, Pizzi LT. Cost of pharmacist-led pneumonia education and immunization program for older Philadelphians.

Durkin M, Moll K, Pasquale MK, Amos T, Null KD. Assessing the impact of varying threshold criteria for opioid overutilization.

Gabriel S, Herrera V, Hoskin B, Anderson $P$, Karagiannis T. Exploring the real world setting of chronic idiopathic urticarial and physician attitudes toward it in the US

Hsiao CW ${ }_{\perp}$ Cheng H, Tao C, Chawla AS, Faulkner EC, DeRamus. Economic benefits of ultrasonic devices in thyroidectomy.

Hsiao CW, Clymer JW, Cheng $\mathrm{H}$ Economic Impact of using harmonic scalpel technology in surgery.

Hsiao CW, Tao C, Chawla AS, Faulkner EC, Cheng $\mathrm{H}$. Blood loss and economic burden components of spinal fusion surgery in adolescent scoliosis and adult deformity.

Jackson J. Health care economic information industry perspective.

Ko JJ, Karagiannis T, Tran M, Obi EN. Crowdsourcing healthcare technology innovation: the use of open competitions to pursue novel healthcare technology solutions.
Park Y, Vegesna A, Ray D, Tsang Y. Oncology drugs receiving breakthrough therapy designation: clinical trial characteristics, drug pricing, and approval process.

Vegesna A, Lieberthal R, Payton C, Sarfaty M, Valko G. Evaluating the cost of patientcentered medical home transformation in small primary care practices.

Vegesna A, Alcusky M, Keith SW, Hegary SE, Del Canale S, Lombardi M, Maio V. Is there an association between potentially inappropriate prescribing in the elderly and hospitalization and mortality? A longitudinal, large cohort study.

Vegesna A, Hazel-Fernandez LA, Boytsov NN, Saundankar V, Yang FE, Nair R, Crawford AG, McAna JF, Altorre Cl. Patient characteristics associated with passing or failing the HEDIS measure for post-fracture osteoporosis management.

\section{JCPH PRESENTATIONS}

Alcusky M, Lieberthal RD. Comparing hospital cost and quality using publicly available data. Poster presented at: AcademyHealth Annual Research Meeting, June 15, 2015, Minneapolis, MN.
Lieberthal RD, Vegesna A, Valko G. Evaluating the cost of patient-centered medical home transformation in small to medium size primary care practices. Poster presented at: North American Primary Research Group Conference, June 29, 2015, Bethesda, MD.
Lieberthal RD. Estimating the cost of $\mathrm{PCMH}$ for small practices: the JUMP Cost Tool. Podium presentation at: AcademyHealth Annual Research Meeting, June 16, 2015, Minneapolis, MN. 


\section{JCPH PUBLICATIONS}

Chawla AS, Hsiao CW, Romney MC, Cohen R, Rubino F, Schauer P, Cremieux P. Gap between evidence and patient Access: policy implications for bariatric and metabolic surgery in the treatment of obesity and its complications. PharmacoEconomics. 2015;33:629-641. Published online June 11, 2015.

Harris D. What is health, anyway? Philly. com. The Field Clinic Blog. May 6, 2015

Harris D. Until N.J. tightens vaccine exemptions, state's children and adults at risk. NJ.com. Star-Ledger Op-ed. May 14, 2015.
Watson LL, Bluml BM, Skoufalos A. Patient credentialing as a population health management strategy: a diabetes case study. Popul Health Manage. 2015; 18(3):179-185.

Mclntire RK, Nelson A A, Macy J T, Seo DC, Kolbe LJ. Secondhand smoke exposure and other correlates of susceptibility to smoking: a propensity score matching approach. Addictive Behaviors. 2015;48:36-43. DOI:10.1016/j. addbeh.2015.04.009.

Nash DB. A new generation of innovators. Medpage Today. May 21, 2015.
Nash DB. Wall Street warming up to population health. Medpage Today. June 18, 2015.

Nash DB. A silver anniversary of the internet. Am Health \& Drug Benefits. 2015; 8(2):63-64

\section{UPCOMING JCPH FORUMS - SUMMER/FALL 2015}

\section{September 9, 2015}

\section{Population Health Readiness}

\section{Wayne H. Giles, MD, MS}

Director of the Division of Population Health

Centers for Disease Control and Prevention (CDC)

Jefferson Alumni Hall (JAH)

1020 Locust Street

Room 307

\section{October 14, 2015*}

\section{Next Generation Payer Strategy}

\section{Minalkumar Patel, MD, MPH}

Senior Vice President and Chief Strategy Officer

Horizon Blue Cross \& Blue Shield of New Jersey

Jefferson Alumni Hall (JAH)

1020 Locust Street

Solis-Cohen Auditorium

*This Forum will be followed by a special Grandon Society

Member-Only program from 9:45 am - 10:45 am.

\section{November 11, 2015}

5 Analytic Imperatives for Successful Population Health Management

Graham Hughes, MD

Chief Medical Officer

SAS Institute's Center for Health Analytics Insights

Bluemle Life Science Building

233 South 10th Street

Room 105/107

\section{December 9, 2015}

Rx for a Better Home: Philadelphia's Healthy Rowhouse Program

\author{
Kiki Bolender, AIA, LEED AP \\ Principal \\ Bolender Architects \\ Jefferson Alumni Hall (JAH) \\ 1020 Locust Street \\ Solis-Cohen Auditorium
}

\section{Forums take place from 8:30 am - 9:30 am and are free of charge.}

For more information call: 215-955-6969.
Forums are designed for Jefferson students, faculty and staff; health care professionals, administrators and advocates; public policy analysts and community health leaders.

For directions and parking visit: Jefferson.edu 


\section{JCPH Health Signs Affiliation Agreement with Rutgers-Camden}

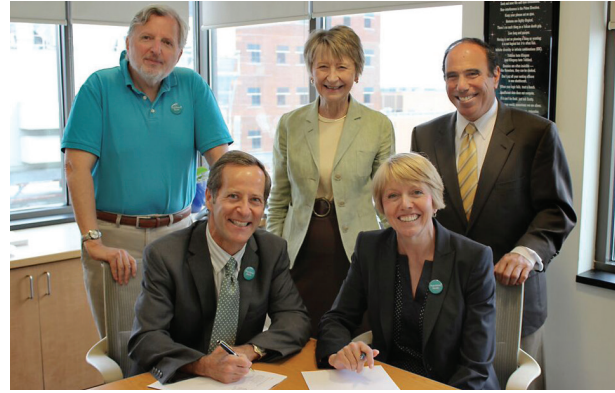

Allen Woll, PhD, Professor of History, Associate Dean for Program Development and Special Projects, Rutgers University-Camden; Caroline Golab, PhD, Rob Simmons, DrPH, MPH, CPH; Dr. Nash and Kriste Lindenmeyer, PhD, Dean, Faculty of Arts and Science, Rutgers University-Camden
$\mathrm{JCPH}$ and Rutgers University-Camden (RUC) recently signed an affiliation agreement that facilitates priority admission of RUC students to the JCPH Master of Public Health (MPH) degree program. RUC students graduating with a bachelor's degree who meet certain criteria with respect to GPA and previous coursework will be assured a space in the $\mathrm{MPH}$ program and will automatically be considered for merit-based scholarships. Eligible RUC students also have the opportunity to take certain courses in the $\mathrm{MPH}$ program during their junior and senior years at a reduced tuition

\section{Dr. Camara Jones Visits Jefferson}

Camara Jones, MD, MPH, PhD, the Director of the Robert Wood Johnson Foundation's Center for Health Policy at Meharry Medical College and the President-Elect of the American Public Health Association (APHA), visited Jefferson's Sidney Kimmel Cancer Center in late May. Prior to delivering a thoughtprovoking talk entitled, "Achieving Health Equity: Addressing Racism and Other Structured System Barriers", she spent time with roughly $20 \mathrm{JCPH}$ faculty, staff, and notable students engaging in a candid dialogue about the importance of public health, both historically and into the future.

Dr. Jones is a family physician and epidemiologist whose work focuses on the impact of racism on the health and wellbeing of the nation. She seeks to broaden the national health debate to include not only universal access to high quality health care but also attention to the social determinants of health, including poverty, and the social determinants of equity, including racism. While speaking with the JCPH group, she shared an allegory that she created to help various audiences understand racism. She likened the flowers in a garden, some that grow tall and strong and others that wither and die, to people. The gardener, who has control in the garden over which flowers flourish and falter, is symbolic of public health professionals. With this allegory, she reminded us that it is our responsibility to promote health equity rate. Students who take designated RUC graduate level courses while completing their undergraduate degree at RUC are eligible to transfer these courses directly into the MPH program, thereby reducing both the time and cost of completing the $\mathrm{MPH}$ degree.

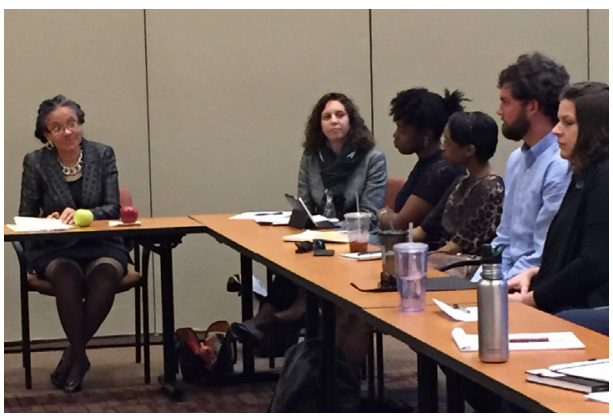

Dr. Jones with Jefferson students and faculty and diminish the structural racism that hinders so many in our society. Dr. Jones is an extremely inspiring researcher, clinician, and teacher-we can't wait to see what she has in store for the APHA when she takes the helm in 2016!

\section{JCPH Alumni Moazzum Bajwa, MD - Medical School Valedictorian}

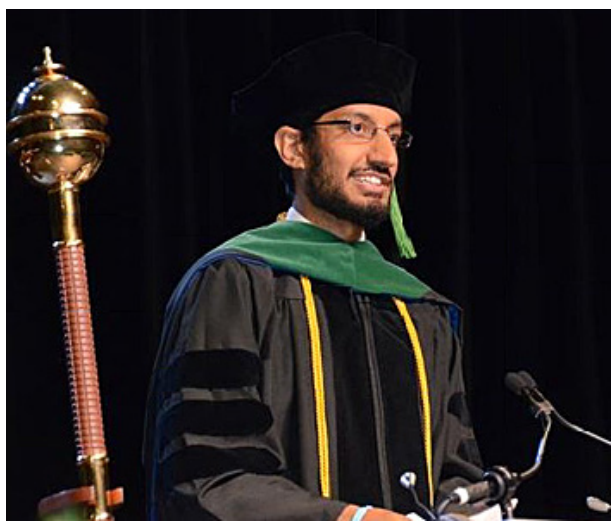

MPH alumni Moazzum Bajwa recently graduated with top honors from Ross University School of Medicine in Dominica, West Indies. "Jefferson and the amazing faculty in the MPH program gave me the tools and confidence to succeed. I worked directly with passionate practitioners who coordinated local projects and influenced policies, all aimed at improving health outcomes" states Dr. Bajwa.

Dr. Bajwa is now in a Family Medicine Residency program at the University of
California, Riverside. He is interested in continuing is work from JCPH by teaching in community health, as well as advocating for policies to enhance access and delivery of care. His goal is to practice fullspectrum family medicine in under-served areas, with an additional focus on Maternal \& Child Health initiatives abroad.

To view Dr. Bajwa's eloquent and entertaining commencement speech click here. 


\section{JCPH IN THE NEWS}

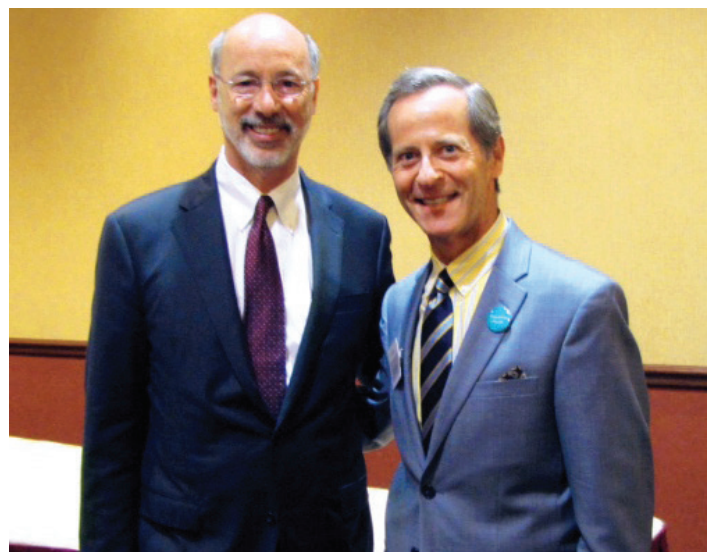

PA Governor Tom Wolf with Dr. Nash at a special healthcare briefing in Harrisburg.

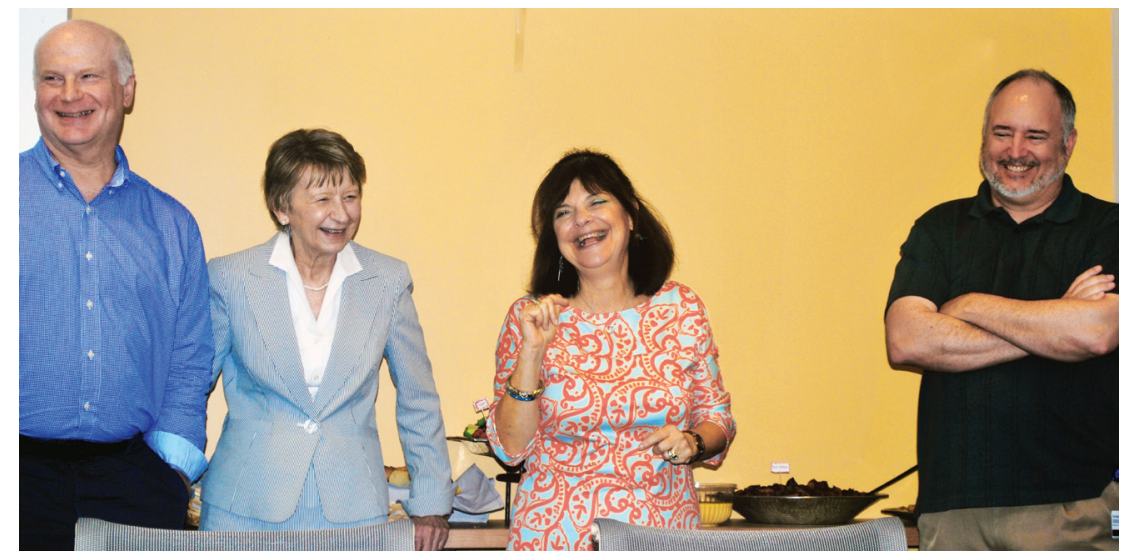

Retirement party for Nancy Chernett.

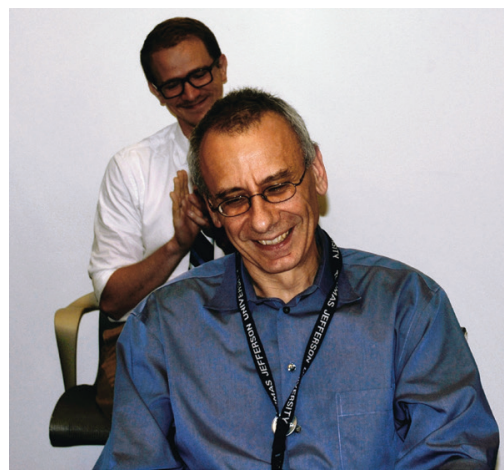

Dr. Vittorio Maio (on left) is honored for his promotion to Professor.

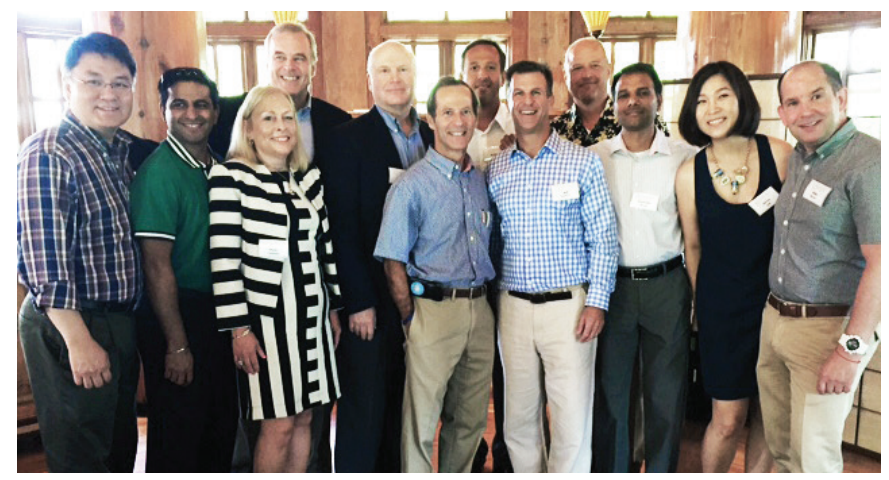

Dr. Nash with J \& J leaders who completed the Health Policy Certificate program.

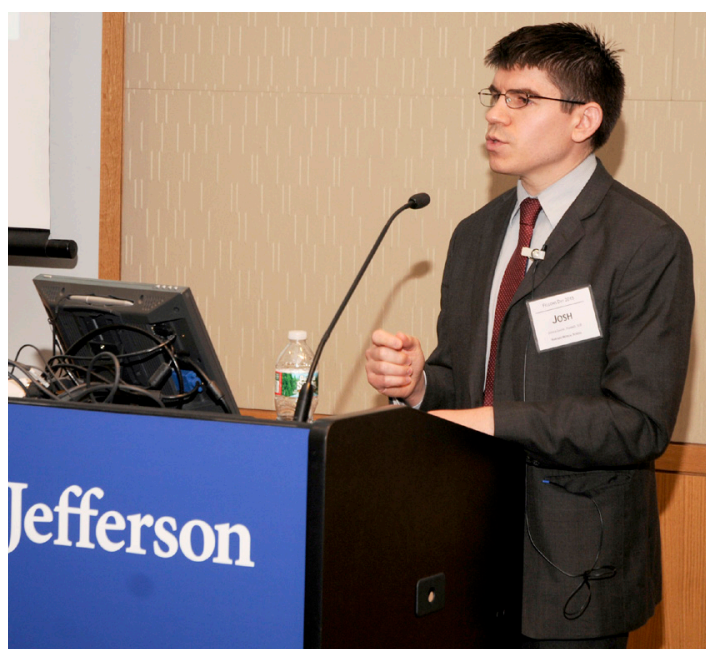

Joshua Gagne, PharmD, ScD, Assistant Professor of Medicine at Harvard Medical School and Fellowship Alumni presents at JCPH Fellows Day.

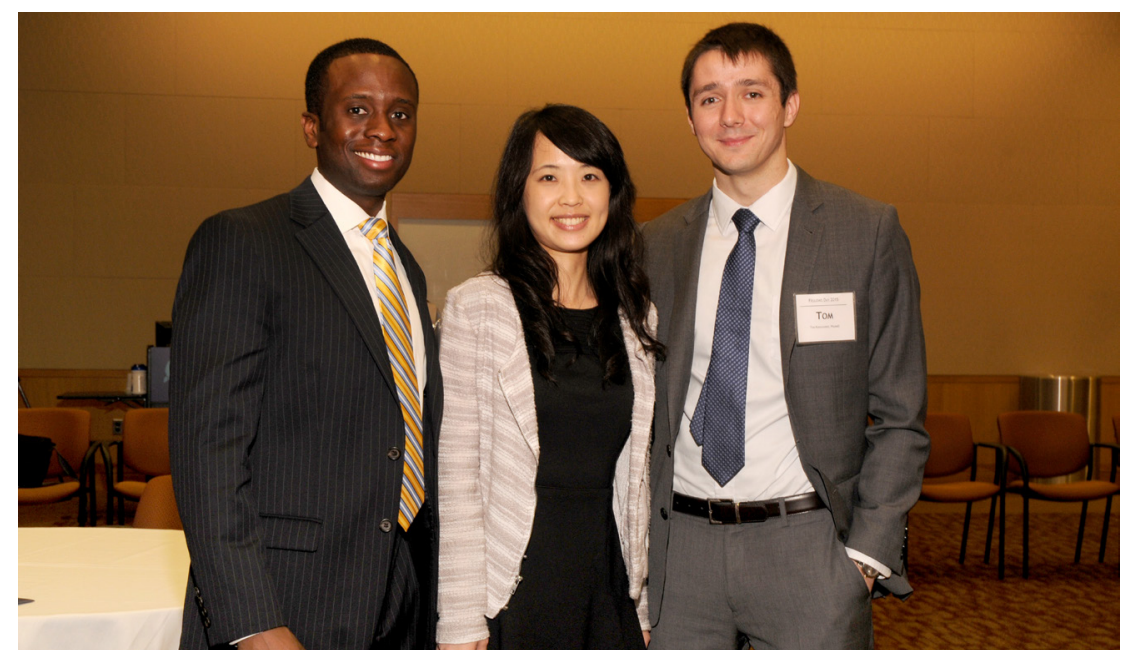

Fellowship Alumni Tony Amos, PharmD, Carine C.W. Hsaio BSPharm, MHS, Tom Karaginannis, PharmD 


\section{Population Health Matters}

Jefferson College of Population Health

Thomas Jefferson University

901 Walnut Street, 10th Floor

Philadelphia, PA 19107

\section{EDITORIAL BOARD}

\section{Editor}

David B. Nash, MD, MBA

Dean

Jefferson College of Population Health

\section{Managing Editor}

Emily J. Frelick, MS

Project Director

Jefferson College of Population Health

\section{Editorial Board}

\section{Lauren Collins, MD}

Associate Director, Jefferson Center for InterProfessional Education

Director, Jefferson Health Mentors Program

Assistant Professor

Division of Geriatric Medicine

Department of Family and

Community Medicine

Sidney Kimmel Medical College

\section{Caroline Golab, PhD}

Associate Dean, Academic and

Student Affairs

Associate Professor

Jefferson College of Population Health

Max Koppel, MD, MBA, MPH

Clinical Associate Professor of Urology Department of Urology

Thomas Jefferson University

\section{Juan Leon, PhD}

Director of Online Learning

Jefferson College of Population Health

Daniel Z. Louis, MS

Managing Director

Center for Research in Medical

Education and Healthcare

Sidney Kimmel Medical College

\section{Kevin Lyons, PhD}

Assistant VP for Program Evaluation and Student Faculty Surveys

Director, Office of Institutional Research

Thomas Jefferson University

Mary Lou Manning, PhD, CRNP,

\section{CIC, FAAN}

Associate Professor

Jefferson College of Nursing

John Melvin, MD

Professor and Chairman

Department of Rehabilitation Medicine

Thomas Jefferson University

\section{Ronald E. Myers, PhD, DSW}

Professor

Director of the Division of Population

Science

Department of Medical Oncology

Sidney Kimmel Medical College
James Pelegano, MD, MS

Program Director, Healthcare

Quality and Safety

Jefferson College of Population Health

Etienne Phipps, PhD

Director

Einstein Center for Urban Health

Policy and Research

Einstein Healthcare Network

Laura Pizzi, PharmD, MPH

Associate Professor

Jefferson College of Pharmacy

\section{Joel Port, MHSA, CHE, CMPE}

Chief Operating Officer

Accountable Care Organization of Pennsylvania

Jefferson Health System

\section{Randa Sifri, MD}

Associate Professor

Director, Research Development

Director, Faculty Development Research

Fellowship Department of Family

and Community Medicine

Thomas Jefferson University
Rob Simmons, DrPH, MPH, MCHES, CPH

Associate Professor

Program Director, Public Health

Jefferson College of Population Health

\section{Alexis Skoufalos, EdD}

Associate Dean

Strategic Development

Assistant Professor

Jefferson College of Population Health

Rachel Sorokin, MD

Chief Patient Safety and Quality Officer Thomas Jefferson University Hospital

Elizabeth Speakman, EdD, RN,

CDE, ANEF

Co-Director

Jefferson Center for

Interprofessional Education

Associate Professor

Jefferson College of Nursing

Richard G. Stefanacci, DO, MGH, MBA, AGSF, CMD

Lecturer, Jefferson College of

Population Health

Chief Medical Officer, The Access Group
901 Walnut Street, 10th Flr. Philadelphia, PA 19107 